\title{
Tartuntatautiepidemian koko, kesto ja välilliset vaikutukset ratkaisevat taloudelliset menetykset
}

\author{
Jarkko K. Niemi ${ }^{1)}$, Tapani Lyytikäinen ${ }^{2)}$, Leena Sahlström ${ }^{2)}$, Terhi Virtanen ${ }^{2)}$ ja Heikki Lehtonen ${ }^{1)}$ \\ ${ }^{1)}$ MTT taloustutkimus, Luutnantintie 13,00410Helsinki,jarkko.niemi@mtt.fi,heikki.lehtonen@mtt.fi \\ ${ }^{2)}$ Evira, Riskinarviointi, Mustialankatu 3,00790 Helsinki, tapani.lyytikainen@evira.fi, \\ leena.sahltrom@evira.fi,terhi.virtanen@evira.fi
}

\section{Tiivistelmä}

Herkästi tarttuvat eläintaudit, kuten suu- ja sorkkatauti, voivat Suomeen levitessään aiheuttaa mittavaa taloudellista vahinkoa. Menetyksiä aiheuttavat mm. taudin hävittämiseen liittyvien toimenpiteiden kustannukset ja kansainväliseen kauppaan liittyvien rajoitusten riski. Riskinhallintatoimien kohdistamiseksi on tärkeää tietää, miten suuria menetyksiä taudinpurkaus voi aiheuttaa ja mitkä tekijät vaikuttavat menetyksiin.

Tutkimuksen tavoitteena oli selvittää, miten suurta taloudellista vahinkoa suu-ja sorkkatautipurkaus voisi aiheuttaa tuottajille, kuluttajille ja veronmaksajille ja mistä menetykset johtuisivat. Tässä keskitytään sikatuotantoon rajoittuvaan tautipurkaukseen ja taloudellisia vaikutuksia tarkastellaan vain sikatalouden osalta. Sikatalous on pitkälle eriytynyt muista tuotantomuodoista, ja vain harvalla sikatilalla on muita eläimiä. Siat eivät ole taipuvaisia saamaan tartuntaa ilmavälitteisesti.

Tutkimusaineistona oli rekisteritietoja, tiloilta ja alan toimijoilta kerättyjä tietoja, sekä aineistoa lihan kulutuksesta, viennistä, hinnoista, tuotantokustannuksista ja taudin hävityksen resurssitarpeista. Suu- ja sorkkataudin leviämistä sikatilojen välillä arvioitiin Monte Carlo-simulaatiomallilla ja tautipurkauksen taloudellisia vaikutuksia sikamarkkinoilla osittaisen tasapainon mallilla. Taudin leviäminen oletettiin mahdolliseksi naapurileviämisenä alle $3 \mathrm{~km}$ säteelle tartuntatilasta sekä tartuntatilalta lähtevän eläinkuljetuksen, eläinkuljetusajoneuvon tai eläinsuojassa tai tilalla käyvän ihmisen välityksellä. Taloudellisia vaikutuksia laskettiin kuluttajille, tuottajille (alkutuotanto ja teurastamot) ja veronmaksajille.

Simuloitujen tautipurkausten kuluttajille, tuottajille ja veronmaksajille aiheuttaman taloudellisen hyvinvointitappion mediaani oli 20,5 miljoonaa euroa. Sikatuottajien menetys oli 25,4 miljoonaa euroa ja veronmaksajien 1,4 miljoonaa euroa. Kuluttajat hyötyivät alentuneista markkinahinnoista 6,3 miljoonaa euroa. Mikäli tauti sattui leviämään monelle tilalle, menetykset saattoivat nousta enimmillään yli 50 miljoonaan euroon.

Taloudelliset menetykset olivat yhteydessä tartuntatilojen määrään, tautipurkauksen kestoon, rajoittavia määräyksiä saavien tilojen määrään ja lihan hintaa alentavaan vientikaupan vähenemiseen. Ensimmäinen tautihavainto aiheuttaakin pääosan menetyksistä, mikäli vientikumppanit toimivat eläintautijärjestö OIE:n ohjeiden mukaan. Suurin tuotantovaikutus liittyi rajoittavien määräysten aiheuttamiin menetyksiin tartunnasta vapaille tiloille.

Taudin maahantulon estäminen on tärkeää. Lisäksi riskinhallinnassa kannattaa kiinnittää huomiota toimenpiteisiin, joilla taudin leviäminen saadaan pysäytettyä ja tauti hävitettyä maasta nopeasti, sekä tuotantomenetysten ehkäisemiseen tartunnasta vapailla tiloilla ja vientimarkkinoilla. Mahdollisia toimenpiteitä ovat mm. taudin seurannan tehostaminen tautivapaana aikana, eläinliikenteen putkitus ja teurastusjärjestelyt suoja- ja valvontavyöhykkeillä.

Asiasanat: eläintaudit, sika, simulointi, hintashokki, tappiot, tuotantohäiriöt 


\section{Johdanto}

Herkästi tarttuvan eläintaudin leviäminen Suomeen voi aiheuttaa mittavaa taloudellista vahinkoa yksittäisille yrityksille ja kansantaloudelle. Esimerkiksi suu- ja sorkkataudin ja klassisen sikaruton kaltaisten eläintautien kohdalla tuotantorakennusten desinfioinnin, kontaminoituneen materiaalin hävityksen, tartuntojen havaitsemiseksi tehtävien tarkastusten ja muiden taudin havaitsemiseen ja maasta hävittämiseen tähtäävien toimenpiteiden kustannukset voivat nousta suuriksi. Tätäkin merkittävämpiä ovat yleensä taudinpurkauksen välilliset vaikutukset, kuten elintarvikeviennin häiriöiden seuraukset tai eläinten hyvinvointiongelmien aiheuttamat kustannukset (mm. Franks ym. 2001, Mangen ja Burrell 2003, Schoenbaum ja Disney 2003).

Riskinhallintatoimenpiteiden valinnan tueksi tarvitaan tietoa siitä, miten suuria menetyksiä tautipurkaus voi aiheuttaa ja miten eri tekijät vaikuttavat menetyksiin. Menetyksiä aiheuttavia tekijöitä tunnistamalla voidaan esimerkiksi kohdistaa toimenpiteet siten, että ne ehkäisevät suurimpia menetyksiä aiheuttavien tapahtumien esiintymistä.

Tutkimuksen tavoitteena oli selvittää, miten suurta taloudellista vahinkoa suu-ja sorkkatautipurkaus voisi aiheuttaa tuottajille, kuluttajille ja veronmaksajille ja mistä menetykset johtuisivat. Tutkimusaineistona oli rekisteritietoja, tiloilta ja alan toimijoilta kerättyjä tietoja, tilastoaineistoa lihan kulutuksesta, viennistä, hinnoista, tuotantokustannuksista ja taudin hävityksen resurssitarpeista. Tutkimusmenetelminä käytettiin Monte Carlo-simulointia, numeerista dynaamista osittaisen tasapainon mallia ja simulaatiotuloksiin sovellettua klusterianalyysia. Tässä keskitytään sikatiloihin rajoittuvaan tautipurkaukseen, koska sikatalous on pitkälle eriytynyt muista tuotantomuodoista ja vain harvalla sikatilalla on muita eläimiä. Siat eivät ole taipuvaisia saamaan tartuntaa ilmavälitteisesti.

\section{Aineisto ja menetelmät \\ Epidemiologinen simulaatiomalli}

Suu- ja sorkkataudin leviämistä sikatilojen välillä arvioitiin Lyytikäisen ja Kallion (2008) kuvaamalla Monte Carlo-simulaatiomallilla. Malli tuottaa kussakin iteraatiossa tartunnan saaneiden tilojen lukumäärän, tartuntatilojen tunnistetiedot sekä taudinpurkauksen keston. Mallissa taudin leviäminen oletetaan mahdolliseksi naapurileviämisenä alle $3 \mathrm{~km}$ säteelle tartuntatilasta sekä tartuntatilalta lähtevän eläinkuljetuksen, eläinkuljetusajoneuvon tai eläinsuojassa tai tilalla käyvän ihmisen välityksellä.

Malli parametrisoitiin vuoden 2006 tiedoilla ja se kuvaa tilannetta, jossa Suomen sikatiloille olisi levinnyt suu- ja sorkkatauti vuonna 2006. Taudin ominaisuuksia kuvaavat tunnusluvut perustuvat aikaisempiin tutkimuksiin (mm. Stevenson 2003, Taylor ym. 2004). Tässä tutkimuksessa keskitytään pelkästään sikatuotantoon rajoittuvaan taudinpurkaukseen. Mallissa taudin leviämisreitit kuvataan rekisteri-ja kyselytietojen avulla. Eläinkuljetusten osalta verkostokuvaus sisältyy eläinkuljetus- ja tilarekistereihin, jotka kuvaavat eläinsiirtojen tapahtuma-ajat, eläinten alkuperän ja päätymispaikan. Naapurileviämisen osalta verkostokuvaus perustuu tilojen sijaintikoordinaatteihin.

Taudin leviämistä ehkäisevät ja sen hävittämiseen tähtäävät toimenpiteet perustuvat suu-ja sorkkatautidirektiivin (Euroopan Komissio 2003). Kun maassa havaitaan esiintyvän suu-ja sorkkatautia, havaitun tartuntatilan ympärille perustetaan suoja- ja valvontavyöhykkeet, joilla olevat tilat tarkastetaan ja eläinten sekä tiloille menevien ja lähtevien ihmisten liikkumista rajoitetaan taudin leviämisen estämiseksi ja mahdollisten tartuntojen havaitsemiseksi. Tutkimusta varten simuloitiin 0,9 miljoonaa taudinpurkausta, jotka aloitettiin vuoronperään kultakin suomalaiselta sikatilalta.

\section{Osittaisen tasapainon malli ja taloudelliset menetykset}

Suu- ja sorkkatautipurkauksen aiheuttamat taloudelliset menetykset määritettiin kahdessa vaiheessa. Ensin määriteltiin tautipurkauksen vaikutus tiloilla olevien eläinten määrään ja siten tuotantoon sekä laskettiin taudin hävittämisestä aiheutuvat suorat kustannukset. Suorilla kustannuksilla tarkoitettiin verovaroista korvattavia kustannuksia, kuten tartunnan saaneiden eläinten lopetuksen ja hävityksen kustannuksia, tiladesinfektioiden kustannuksia, näytteenotosta, tilojen tarkastuksista ja muusta viranomaisten toiminnasta aiheutuvia suoria kustannuksia. Suorien kustannusten laskennassa hyödynnettiin Iso-Britannian 2001 epidemiasta kerättyjä tietoja (Risk Solutions 2005), eläinlääkäreille laadittuja toimintaohjeita sekä MTT:n ja Eviran tutkimusta (Niemi ym. 2008).

Toiseksi tautipurkauksen tuotantovaikutuksia ja kestoa kuvaavia tietoja käytettiin numeerisessa osittaisen tasapainon mallissa tautishokkina (Kuva 1). Mallilla tutkittiin taudinpurkauksen vaikutusta kuluttajien (sis. kauppa) ja tuottajien (sis. teurastamot) taloudelliseen ylijäämään. Malli maksimoi sikasektorin 
tuottaman ylijäämän yli ajan ja minimoi samalla tautishokista aiheutuvan kustannuksen. Mallin tuottama ratkaisu perustuu stokastisen dynaamisen ohjelmoinnin menetelmään. Osittaisen tasapainon mallilla simuloidaan, miten suu- ja sorkkatautipurkaus ja siihen liittyvä ulkomaankaupan häiriintyminen vaikuttaa sianlihan tuotantoon, vientiin, tuontiin ja markkinahintoihin Suomessa kuukausitasolla. Vienti jaetaan EU-maihin ja EU:n ulkopuolisiin maihin kohdistuvaan vientiin, jolloin voidaan tarkastella EU:n ja muiden maiden reaktioiden vaikutuksia tautipurkauksen aiheuttamiin menetyksiin.

Malli simuloi eläintuotantokapasiteetin käyttöasteesta, lisääntyneestä uudistustarpeesta ja eläinten poistoista aiheutuvat kustannukset. Sekä tuotanto että kulutus voivat sopeutua taudinpurkauksen aiheuttamaan häiriöön, mutta tuotannon sopeutumista hidastaa lyhyt aikajänne, sillä emakoiden määrää ja siten lihan tuotantoa voidaan lisätä vasta usean kuukauden tai jopa vuoden aikajänteellä. Lihan hinta on keskeinen tuotanto- ja kulutuspäätöksiin vaikuttava tekijä (Kuva 1).

Osittaisen tasapainon mallin parametrisoimiseksi estimoitiin sianlihan vientikysyntöjä, tuontikysyntää ja kotimaan kysyntää kuvaavat yhtälöt. Yhtälöt estimoitiin kolmivaiheisella pienimmän neliösumman menetelmällä. Tämän menetelmän avulla voitiin korjata estimointivirhe, joka aiheutuu siitä, että suomalaisen tuotteen hinta on endogeeninen. Tuotantokustannusrakenne perustuu ProAgrian (2007) tilamallilaskelmiin sekä lihasikatuotannon osalta osittain myös Niemen (2006) siankasvumalliin.

Tasapainomallissa taudinpurkauksesta seuraa sianlihan viennin keskeytyminen. Keskeytys kohdistuu skenaariosta riippuen joko EU:n ulkopuoliseen vientiin tai kaikkeen vientiin. Vientihäiriön kestoksi oletettiin ensimmäisen tautihavainnon ja viimeisten rajoittavien määräysten poistamisen välinen aika lisättynä kolmella kuukaudella. Skenaario perustui siten epidemiologisiin simulaatioihin ja eläintautijärjestö OIE:n (2007) suosituksiin. Vientihäiriön toteutunut kesto on mallissa stokastinen ja ennalta tuntematon, mutta sen odotettu kesto tunnetaan. Häiriön vaikutusta tuloksiin tarkastellaan sekä häiriön odotetun keston että vientimarkkinoiden sulkeutumisasteen (koko vienti keskeytyy, EU:n ulkopuolinen vienti keskeytyy) näkökulmasta.

Jokaisella hetkellä sikamarkkinoita voidaan kuvata kolmella tilannemuuttujalla, jotka olivat tuotannossa olevien emakoiden lukumäärä, kasvatettavana olevien lihasikojen ja porsaiden lukumäärä sekä vientimarkkinoiden tilanne (vienti häiriintynyt tai vienti ei häiriintynyt). Taudinpurkauksesta aiheutuvat menetykset laskettiin arvofunktion erotuksena tilanteista, jossa vienti on ja ei ole häiriintynyt, sillä viennin häiriintyminen on yhteydessä taudinpurkauksen esiintymiseen. Niemi ja Lehtonen (2008) kuvaavat mallin yksityiskohtaisemmin.

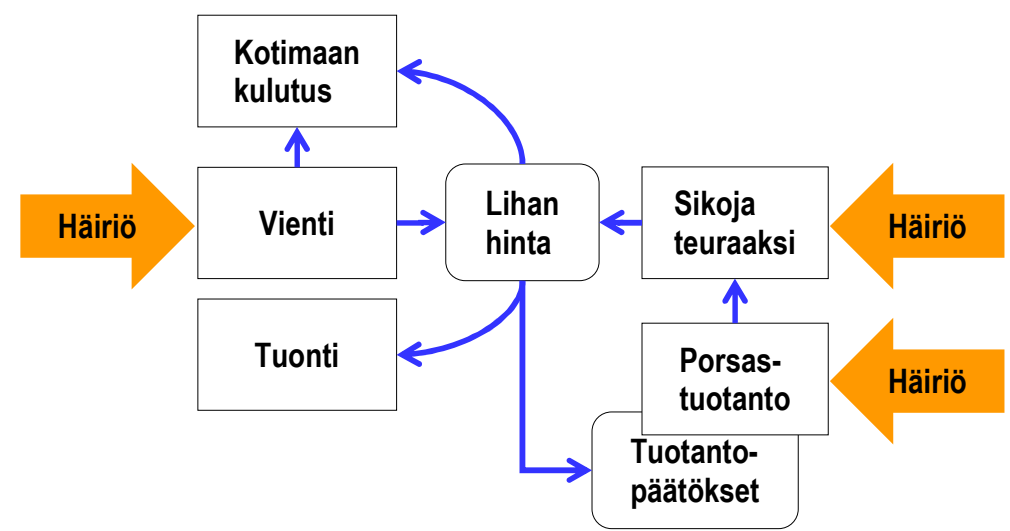

Kuva 1. Osittaisen tasapainon mallilla simuloidaan taudinpurkaukseen liittyvän vientihäiriön sekä taudin vuoksi markkinoilta poistuvien eläinten vaikutukset sianlihan hintaa, kysyntään ja tuotantopääöksiin.

\section{Tulokset ja tulosten tarkastelu}

Mediaanitapauksessa tautipurkaus aiheuttaisi yhteiskunnalle 20,5 miljoonan euron tappiot, mutta pahimmillaan sikatuotannolle ja veronmaksajille aiheutunut menetys nousee yli 50 miljoonaan euroon. Kun mediaanitapauksen taloudellisia vaikutuksia tarkastellaan eturyhmittäin, tuottajat häviäisivät 25,4 miljoonaa euroa ja veronmaksajat 1,4 miljoonaa euroa. Sen sijaan kuluttajat hyötyisivät 6,3 milj. $€$. Taudinpurkauksen aiheuttamat menetykset koostuisivat pääasiassa vientihäiriöistä ja vähemmässä määrin taudin hävitykseen liittyvistä toimista ja tuotantohäiriöistä, joiden laajuus riippuu suoja- ja valvontavyöhykkeillä olevien tilojen ja eläinten määrästä. Suurimmissa tautipurkauksissa verovaroista korvattavat suorat menetykset voivat olla 
huomattavat.

Tuottajien kärsimä tappio johtuu pääosin sianlihan viennin äkillisestä häiriintymisestä seuraavasta ylitarjontatilanteesta, hinnanalennuksista ja markkinointivaikeuksista. Osa tuottajien tappiosta koituu kuluttajien ja kaupan hyödyksi, mutta pääosin tuottajien kokemasta tappiosta on peruuttamattomia markkinatuottojen menetyksiä ja tähän liittyviä sopeutumiskustannuksia, joita ei saada myöhemmin enää takaisin. Tautipurkauksen taloudellinen vaikutus koko yhteiskunnalle on selvästi negatiivinen. Vientishokista aiheutuvan menetyksen suuruus on voimakkaasti yhteydessä tautipurkauksen ja vientihäiriön kestoon. Menetykset ovat hieman suuremmat, mikäli sianlihan vienti keskeytyisi kokonaan sen sijaan että vienti EU-markkinoille olisi mahdollista tautialueiden ulkopuolella sijaitsevilta tiloilta ja teurastamoista. Taudin esiintymisen ei oleteta vaikuttavan sianlihan kysyntään Suomessa, koska tauti ei heikennä elintarvikkeiden turvallisuutta ja koska Länsi-Euroopassa puhjenneissa tartuntatautiepidemioissa tällaiset vaikutukset ovat yleensä olleet vähäisiä. Kuluttajat ja kauppa voivat hyötyä hinnanalennuksista mm. korvaamalla tuontilihan kulutusta kotimaisen lihan kulutuksella. Siten lihan tuonti vähenisi hintojen laskiessa. Mikäli tautipurkaus poistaisi runsaasti eläimiä markkinoilta, tuottajahintataso saattaisi vientimarkkinoille pääsyn palauduttua nousta tautivapaata aikaa korkeammaksi. Simuloiduissa tautipurkauksissa tämä vaikutus on kuitenkin vähäinen, sillä toisin kuin EU:n voimaperäisimmillä kotieläintuotannon alueilla, tautipurkauksen välitön vaikutus tuotantoon jäi Suomessa pieneksi.

Kun lasketaan samalta tilalta alkaneiden tautipurkausten keskiarvot ja verrataan tilojen välisiä eroja menetyksissä, tappiot kasvavat a) epidemian todennäköisyyden, b) tartuntatilojen määrän, c) rajoittavat määräykset saaneiden tilojen (tartuntatilat, suojavyöhyketilat ja valvontavyöhyketilat) määrän suhteessa tartuntatilojen määrään ja d) purkauksen keston kasvaessa (Kuva 2). Tekijät a-d korreloivat keskenään. Kuvassa 2 vientihäiriö keskeyttää sianlihan viennin Suomesta kokonaan.

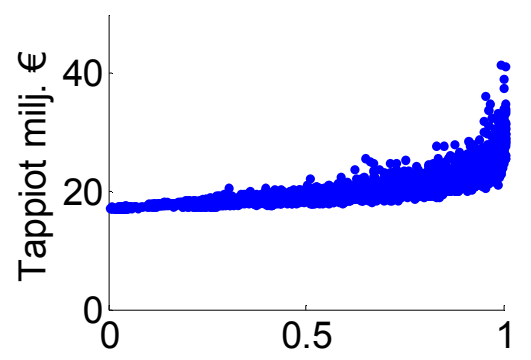

a) Todennäköisyys

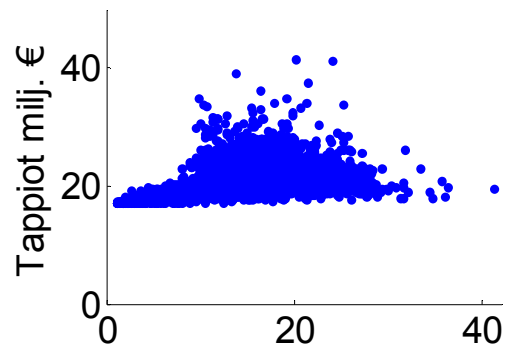

c) Rajoittavia määräyksiä

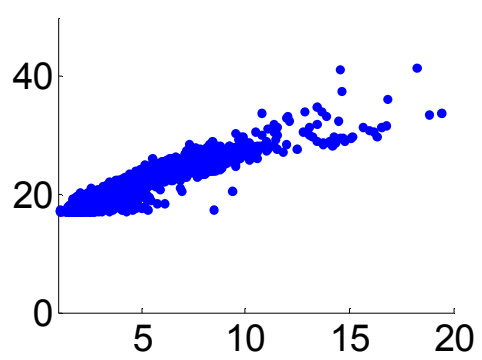

b) Tartuntatiloja

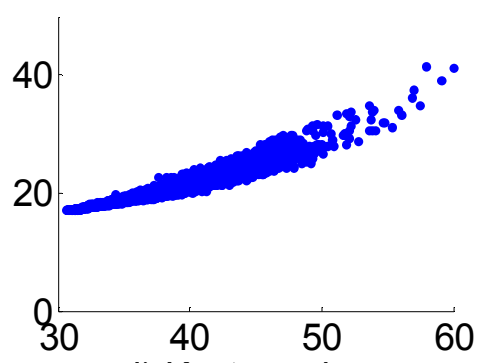

d) Kesto, päivää

Kuva 2. Tautipurkauksen aiheuttaman tappion yhteys epidemian todennäköisyyteen (a), tartuntatilojen odotettuun määrään (b), yhtä tartuntatilaa kohti rajoittavat määräykset saavien tilojen määrään (c) sekä taudinpurkauksen odotettuun kestoon (d), kun kukin piste edustaa samalta tilalta alkaneiden taudinpurkausten keskivertovaikutusta.

\section{Johtopäätökset}

Tulosten mukaan välilliset vaikutukset ja niiden kesto aiheuttavat pääosan taudinpurkauksen taloudellisista menetyksistä. Vientikiellon aiheuttama tuottajahintojen lasku vähentää kaikkien tuottajien tuloja. Suurissa taudinpurkauksissa myös suorat tappiot sekä eläinkannan väheneminen voivat aiheuttaa merkittäviä taloudellisia menetyksiä. Koska vientihäiriö seuraa jo ensimmäisestä tartunnasta, on tärkeää estää taudin pääsy Suomeen. Myös taudin nopea havaitseminen, leviämisen pysäyttäminen ja nopea taudin hävitys ovat tärkeitä, koska näin voidaan vähentää tartuntatilojen määrää sekä menetyksiä tartunnasta vapailla tiloilla ja vientimarkkinoilla. 


\section{Kirjallisuus}

Euroopan Komissio. 2003. Council Directive 2003/85/EC of 29 September 2003 on Community measures for the control of foot-and-mouth disease repealing directive 85/511/EEC and decisions 89/531/EEC and 91/665/EEC and amending directive 92/46/EEC. Official Journal of the European Union L306:1-87

Franks, J., Lowe, P., Phillipson, J. \& Scott, C. 2001. The impact of foot and mouth disease on farm businesses in Cumbria. Land Use Policy 20: 159-168.

Lyytikäinen, T. \& Kallio, E. 2008. Risk classification of Finnish pig farms by simulated foot and mouth disease spread. Julkaisussa: E.J. Peeler, L. Alban, A. Russell, and the SVEPM Executive Committee, Eds. Society for Veterinary Epidemiology and Preventive Medicine, Proceedings of a meeting held at Liverpool, UK 26th-28th of March 2008. pp. 285-300.

Mangen, M.-J.J. \& Burrell, A.M. 2003. Who gains, who loses? Welfare effects of classical swine fever epidemics in the Netherlands. European Review of Agricultural Economics 30:125-154.

Niemi, J.K. 2006. Dynamic programming model for optimising feeding and slaughter decisions regarding fattening pigs. Agricultural and Food Science 15, Supplement 1: 1-121. Saatavilla Internetissä: http://urn.fi/URN:ISBN:951729-997-4

Niemi, J.K. \& Lehtonen, H. 2008. The value of market uncertainty in a livestock epidemic. Poster paper presented at AAEA annual meeting, Orlando, FL, 27-29 July 2008. Saatavilla Internetissä: http://purl.umn.edu/6158

Niemi, J.K., Lehtonen, H., Pietola, K., Lyytikäinen, T. \& Raulo, S. 2008. Economic implications of potential classical swine fever outbreaks for Finnish pig production sector. Preventive Veterinary Medicine 84: $194-212$. OIE. 2007. Terrestrial animal health code. 2007. Office International des Epizooties, Paris.

ProAgria. 2006. Tuottopehtoori. ProAgria keskusten liitto, Vantaa. Viitattu 18.2.2009. Saatavilla Internetissä: http://www.agronet.fi/cgi-bin/mkl/julk/malli.cgi.

Risk Solutions. 2005. FMD CBA epidemiological model specification and description. A report for Defra, May 2005. Viitattu 30.4.2009. Saatavilla Internetissä:

http://www.defra.gov.uk/animalh/diseases/fmd/pdf/epidem_model.pdf.

Schoenbaum, M. A. and Disney, W. T. 2003. Modeling alternative mitigation strategies for a hypothetical outbreak of foot-and-mouth disease in the United States. Preventive Veterinary Medicine 58: 25-52.

Stevenson, M.A. 2003. The spatio-temporal epidemiology of bovine spongiform encephalopathy and foot-andmount disease in Great Britain. Ph.D. Thesis. Institute of Veterinary, Animal and Biomedical Sciences, Massey University, Palmerston, New Zealand. 249 p.

Taylor, N.M, Honhold, N, Paterson, A.D. \& Mansley, L.M. 2004. Risk of foot-and-mouth disease associated with proximity in space and time to infected premises and the implications for control policy during the 2001 epidemic in Cumbria. Veterinary Record 155: 646-647. 